\title{
Unusual survival of an adult with pleuropulmonary blastoma and neurofibromatosis
}

\author{
Noah B. Zuker, MD, ${ }^{a}$ Charles A. Dietl, MD, ${ }^{\mathrm{b}}$ Sherry Kenna, RN, ${ }^{\mathrm{b}}$ Edgar G. Fischer, MD, PhD, ${ }^{\mathrm{c}}$ and David Gardner, MD, \\ Albuquerque, New Mexico
}

A

19-year-old white man, with neurofibromatosis type I, optic glioma, and history of blebectomy for spontaneous left pneumothorax at age 17 years, presented to the University of New Mexico Health Sciences Center with chronic pain in the left side of his chest.

\section{Clinical Summary}

Chest radiography showed a solid mass encased within a large cystic structure, suspicious for aspergilloma of the left lung. A chest computed tomographic scan revealed a huge multiseptated cystic structure involving the entire major fissure of the left lung, containing a multilobulated soft tissue mass (Figure 1), and measuring approximately $10 \times 20 \mathrm{~cm}$. The mass and cysts were completely excised through a left thoracotomy. The specimen weighed $85 \mathrm{~g}$ in aggregate and consisted of thin-walled cysts, imparting a botryoid (ie, grape-like) appearance, with minor solid components (Figure 2, A). Microscopically, small immature tumor cells with ovoid to spindle-shaped nuclei were set in a myxoid stroma. Cellularity was highest in the so-called cambium layer just beneath the attenuated cyst lining (Figure 2, B). Tumor cells were positive for desmin and other muscle markers by immunohistochemistry. A diagnosis of pleuropulmonary blastoma (PPB) type II was made. The patient's postoperative course was uneventful. Retrospective pathologic examination of the blebectomy specimen obtained 2 years earlier revealed subtle histologic features suggestive of PPB type I. The patient received a multidrug regimen of 11 cycles of chemotherapy, consisting of vincristine, actinomycin, and cyclophosphamide during the first phase, and doxorubicin (Adriamycin; Bedford Laboratories, Bedford, Ohio), cisplatin, and doxorubicin during the second phase. Follow-up computed tomography scans of the chest, abdomen, and pelvis revealed no evidence of recurrence or metastasis at 24 months. The patient is currently asymptomatic with good weight gain and normal physical strength.

From the Department of Surgery, ${ }^{\text {a }}$ Division of Thoracic and Cardiovascular Surgery; and Departments of Surgery ${ }^{\mathrm{b}}$ and Pathology, ${ }^{\mathrm{c}}$ University of New Mexico Health Sciences Center, Albuquerque, New Mexico.

Received for publication April 14, 2007; accepted for publication April 26, 2007.

Reprint requests: Charles A. Dietl, MD, Thoracic and Cardiovascular Surgery, Department of Surgery (ACC-2), University of New Mexico Health Sciences Center MSC 10 5610, Albuquerque, NM 87131-0001 (E-mail: CDietl@salud.unm.edu).

J Thorac Cardiovasc Surg 2007;134:541-2

$0022-5223 / \$ 32.00$

Copyright $@ 2007$ by The American Association for Thoracic Surgery doi:10.1016/j.jtcvs.2007.04.032

\section{Discussion}

This case report demonstrates the cardinal clinical and pathologic features of PPB, a highly aggressive childhood malignancy, in an adult. These tumors present almost exclusively in the first decade of life. ${ }^{1}$ To our knowledge, 4 adult patients have been reported in the literature, with only 1 survivor at 29 months, after radiation therapy of a nonresectable PPB. ${ }^{2}$ It is now recognized that $25 \%$ of PPB cases occur in a familial setting with other tumors of childhood, such as cystic nephroma, rhabdomyosarcoma, and synovial sarcoma. ${ }^{3}$ There are no reports in the literature of any case of PPB associated with neurofibromatosis. Clinical presentation of these rare tumors may vary from ruptured lung blebs, as in our patient, or space-occupying masses resembling a mediastinal teratoma ${ }^{4}$ to more subtle manifestations of chest pathology or systemic disease. The clinical and radiographic differential diagnosis includes fungal lesions, congenital cystic adenomatoid malformation, bronchogenic cyst, and postinfectious pneumatocele.

Three pathologic types of PPB have been described: Type I is purely cystic and may present as a congenital lung cyst; type II is a combined cystic and solid tumor; and type III is solid and can be accompanied by hemorrhage and necrosis. ${ }^{2}$

The potential for malignant transformation of mesenchymal elements is emphasized by our case. The tendency for PPB to transform from type I to type II after resection or possibly during ontogeny is also illustrated by case reports with close follow-up and early aggressive surgical resection of lung cysts in children. ${ }^{5}$ Further study may determine the effectiveness of prophylactic resection in the absence of symptomatic disease.

The prognosis of pediatric patients affected with PPB is poor. The largest case series reported an $83 \%$ 5-year survival for type I and a $42 \%$-year survival for types II and III. ${ }^{1}$ Concomitant

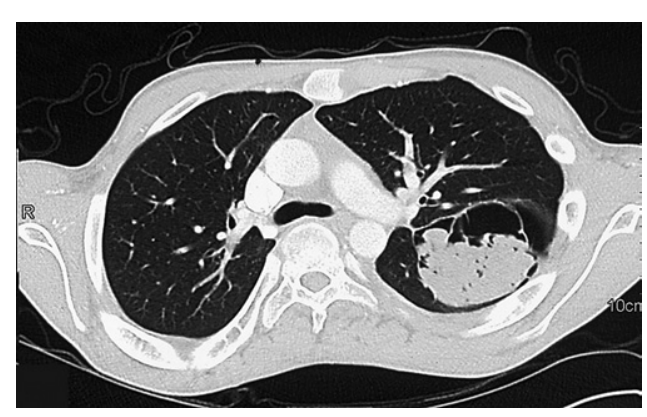

Figure 1. Chest computed tomographic scan showing a huge multiseptated and multilobulated mass involving the entire major fissure of the left lung. 

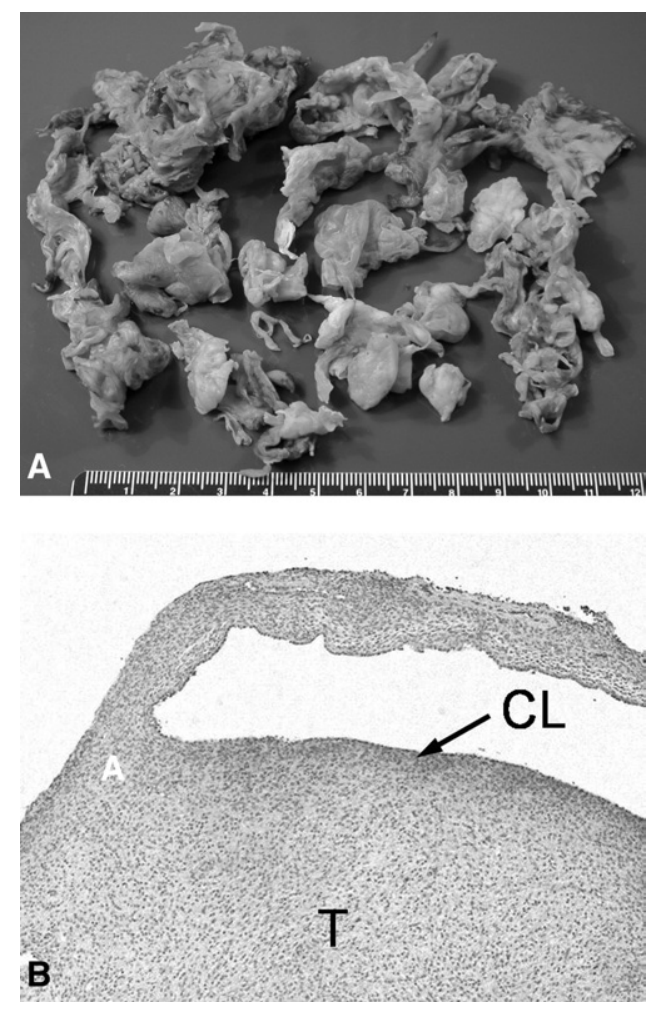

Figure 2. A, Gross appearance of the resected tumor with thinwalled cysts imparting a botryoid appearance. B, Intermediatepower photomicrograph showing the ill-defined cambium layer with increased cellularity beneath the cyst lining (magnification $40 \times$ ). CL, Cambium layer; $T$, tumor. analysis of gene expression will be useful in determining adjuvant chemotherapeutic regimens for rare cancers with documented gene expression patterns. The nexus of multidisciplinary approaches will generate an optimal treatment strategy for this complex disease, as advocated by several studies.

Three conclusions can be drawn from this rare case: PPB should be considered in the clinical and radiographic differential diagnosis when fungal disease or a congenital malformation is suspected, even when the patient is a young adult; PPB can be associated with neurofibromatosis type I, which has not been described before; and, PPB in young adults could have a less aggressive clinical course, but more experience is necessary with patients in this age group.

\section{References}

1. Priest JR, McDermott MB, Bhatia S, Watterson J, Manivel JC, Dehner LP. Pleuropulmonary blastoma: a clinicopathologic study of 50 cases. Cancer. 1997;80:147-61.

2. Kamenova B, Braverman AS, Axiotis CA, Sohn C, Goff DJ. Complete remission of an unresectable pleuropulmonary blastoma in an adult after radiation therapy. Am J Clin Oncol. 2006;29:641-2.

3. Boman F, Hill DA, Williams GM, Chauvenet A, Fournet JC, Soglio $\mathrm{DB}$, et al. Familial association of pleuropulmonary blastoma with cystic nephroma and other tumors: a report from the International Pleuropulmonary Blastoma Registry. J Pediatr. 2006;149:850-4.

4. Lee CH, Kim KI, Kim YD, Lee MK, Kim JY, Park DY, et al Pleuropulmonary blastoma in a young adult presenting as a ruptured cystic teratoma in radiology. J Korean Med Sci. 2003;18:595-8.

5. Dosios T, Stinios J, Nicolaides P, Spyrakos S, Androulakakis E, Constantopoulos A. Pleuropulmonary blastoma in childhood: a malignant degeneration of pulmonary cysts. Pediatr Surg Int. 2004;20: 863-5. 